\title{
Socio-Professional Adaptation of the Military Personnel Transferred to the Reserve (Research Made in the Ulyanovsk Region, Russia)
}

\author{
Tatyana A. Chertushkina ${ }^{1}$, Natalia B. Shmeleva ${ }^{1}$, Oksana V. Shabanova ${ }^{1}$, Irina A. Solodovnikova ${ }^{1}$, Elena N. \\ Lvova $^{1} \&$ Maria V. Shmeleva ${ }^{1}$ \\ ${ }^{1}$ Ulyanovsk State University, Ulyanovsk, Russian Federation \\ Correspondence: Tatyana A. Chertushkina, Ulyanovsk State University, ul. L.Tolstogo 42, Ulyanovsk, 32017, \\ Russian Federation. Tel: 7-908-482-8879. E-mail: ta-chertushkina@yandex.ru
}

$\begin{array}{lrr}\text { Received: March 22, } 2015 & \text { Accepted: April 8, } 2015 \quad \text { Online Published: July 24, } 2015 \\ \text { doi:10.5539/res.v7n11p132 } & \text { URL: http://dx.doi.org/10.5539/res.v7n11p132 }\end{array}$

\begin{abstract}
The urgency of the researched problem is caused by the necessity to improve the mechanism of socio-professional adaptation of the military personnel transferred to the reserve.

The article is directed on detection of the features of the social and psychological and professional status of former military personnel before the transition to civil professional activity. It deals with the definition of the general algorithm of work on socio-professional adaptation of this category of citizens.

During the research there were used such main methods as content analysis, diagnostic and empirical methods, cluster analysis.

The main results of the article consist of the definition of the psychological resources and qualities which promote the formation of an independent personality of the former military personnel in the course of socio-professional adaptation. The article represents the system of actions and the general algorithm of work on socio-professional adaptation of the military personnel transferred to the reserve.

The materials of the article can be useful for the experts of military commissariats, the employees of job centers, the social workers, whose professional activity is connected with the military personnel transferred to the reserve.
\end{abstract}

Keywords: retired military personnel, adaptation, socio-professional adaptation, social work

\section{Introduction}

The Russian state has put forward a set of measures aimed at improving the state mechanism in the course of reforms in the economic, political and socio-cultural spheres, including its military organization.

The first stage of reforms of Russian armed forces began in 2008 and was completed in 2011 (Reform of Armed forces of Russia (2008-2020)). The total number of the armed forces of the Russian Federation was reduced to 1 million people. Most of the reductions occurred in the officer corps: the reform reduced approximately 200 thousand officer positions. The institution of warrant officers and midshipmen which numbered about 140 thousand people was also eliminated (Reform of the Armed Forces of Russia, 2008-2020).

As a result of the implementation of all planned decisions of Russian highest political leaders there were a considerable number of officers, persons of non-commissioned officers and ordinary structures of different age. All of them had to find their places in civil life. Many former military personnel joined the ranks of the jobless citizens professionally unclaimed in the society. This fact, in its turn, raises the extent of threat of stress and neurologic diseases accompanying it. There is also a growing tension in various structures and centers of social sphere giving social help and support to people. Now in the Ulyanovsk region there are more than 9 thousand military personnel transferred to the reserve, $40 \%$ of them are of working-age. This category of citizens needs social and professional adaptation.

Socio-professional adaptation is a process of adaptation of a person to professional activity, working conditions and a new labor group. Besides it includes the achievement of the demanded labor productivity at the optimum short period of time.

The transition of military personnel transferred to the reserve to civil professional activity is connected with 
overcoming difficulties caused by the need of entry into the system of new social and labor relations, adaptation to the conditions of dynamically emerging labor market, restoration of competitive force in the sphere of professional work in the civil reality.

Special attention should be paid to the fact that the solution of the problems of the military personnel transferred to the reserve should be the matter of not only the organizations, but of specially trained qualified specialists in social work. In each case it is necessary to consider the features of social and psychological and professional status of the soldier discharged from military service because the sphere of military work has no practical communication with general labor market.

\section{Materials and Methods}

The purposes and the research problems defined the choice of the following methods of research: analysis and the content analysis of pedagogical, psychological and special literature, standard and legal documents; diagnostic methods (testing, assessment); empirical methods (supervision \& introspection); polling methods (conversation, interview, questioning). During the research the graphic interpretation of results of research was carried out. The mathematical methods of the analysis of the obtained data played an important role in the research, the cluster analysis in particular.

Within the project there was a practical research directed on socio-professional adaptation of the military personnel transferred to the reserve. It consists of carrying out questioning, testing for the definition of the professional type of a person after J. Golland (G. V. Rezapkina's modification).

The practical course "How to make the curriculum vitae", the role game-interview "Examples of Answers to Typical Interview Questions" were also among practical measures. 68 military men transferred to the reserve aged from 41 to 49 years took part in the research conducted on the basis of Federal public budgetary educational institution of higher education Ulyanovsk State University".

\section{Results}

The results of questioning were as follows: for most of the participants (71\%) the aspiration to retrain is characteristic. Choosing the specialty on which they would like to pass retraining, respondents consider such signs as reliability, an employment guarantee (53\%), high salaries (47\%), saving of the social status (35\%), easy and fast development in a profession $(26 \%)$.

The most attractive specialties for retraining are as follows: an expert in information technologies (IT) (41\%), an economist, a lawyer, a teacher of higher educational institutes, a builder, office workers, engineers, managers in the sphere of the organization of production.

Thus the preference is given to the training centers of the employment service $(47 \%)$, training centers on the basis of higher education institutions (26\%), to training centers at enterprises $(17 \%)$, and for some respondents the organization carrying out retraining doesn't matter at all (10\%).

Retraining level for the military personnel has a great meaning. Obtaining a diploma on the second higher education is important for the vast majority of them (71\%).

Preferable terms of training for respondents are from six months (41\%) to one year (35\%).

An important factor for the military personnel transferred to the reserve is availability of information on the situation in the labor market (41\%), information about the employment prospects on the existing specialty (26\%), information on the availability of employment prospects on the received profession (21\%), the possibility of self-employment (12\%). Practically all respondents (82\%) noted that they needed a consultation of specialists in the sphere of employment. The main aims of work of the employment structures marked by respondents are selection of permanent, temporary or suitable job (41\%); putting professional interests and claims of a person in accordance to the situation at the labor market, definition of the most acceptable options of professional retraining( $25 \%$ ), informing a person on his/her real situation and prospects in labor market (29\%), carrying out psychological diagnostics, detection of social, psychological and physiological characteristics of a person (5\%). The participants of the research of 40 years old and older have additional difficulties in employment but they consider health, good support of the state, personal qualities, self-confidence, education and a good profitable specialty as well as money and good relations to be necessary for promotion in the professional sphere.

After questioning a number of military men transferred to the reserve were offered to pass a test for definition of professional type of the personality by J. Golland (G. V. Rezapkina's modification). Each profession in the test material corresponds to one of the six types of the personality. In the key it is specified, which profession corresponds to this or that type of the personality. For example, answering question No. 1 the respondent chooses 
"option A". According to the key, this profession corresponds to the realistic type of the personality. We add one point in favor of the realistic type of the personality. If he chooses "option B", according to the key, it will be necessary to add one point in favor of the social type of the personality.

Designations in the key correspond to the first letter of the personality: R-Realistic, S-Social, I-Intellectual, $\mathrm{O}$-Office, E-Entrepreneurial, A-Artistic.

If a respondent gains 8-10 points he/she is the pronounced type of personality; 5-7 points mean medium expressed type of personality; 2-4 points mean poorly expressed type.

The greatest number of points indicates the dominating type. In pure form these professional types can be seldom seen, so it is usually possible to speak only about the prevailing type of the personality. Choosing a profession, it is necessary to consider the professional type. If profession doesn't correspond to your type of personality, you will face a considerable psychological tension. According to the results of testing the following data (Figure 1) were obtained: $18 \%$ of participants of the research had expressed high realistic type, $41 \%$ of them had medium expressed type and $41 \%$ of the respondents had poorly expressed type.

$24 \%$ of participants of the testing had expressed intellectual type, $41 \%$ of the participants had medium expressed intellectual type and $35 \%$ of the participants had poorly expressed intellectual type.

The social type was expressed by $24 \%$ of the respondents, the social type was medium expressed by $29 \%$ of the respondents and for $47 \%$ of respondents this type was poorly expressed.

The office type was expressed by $29 \%$ of the participants of the research, the office type was medium expressed by $24 \%$ of participants and $47 \%$ of respondents had poorly expressed office type.

The entrepreneurial type was expressed by $12 \%$ of respondents, $35 \%$ of respondents had it medium expressed and this type was poorly expressed by $53 \%$ of respondents.

The artistic type was expressed only by $6 \%$ of participants of the research, this type was medium expressed by $29 \%$ of respondents and it was poorly expressed by $65 \%$ of respondents.

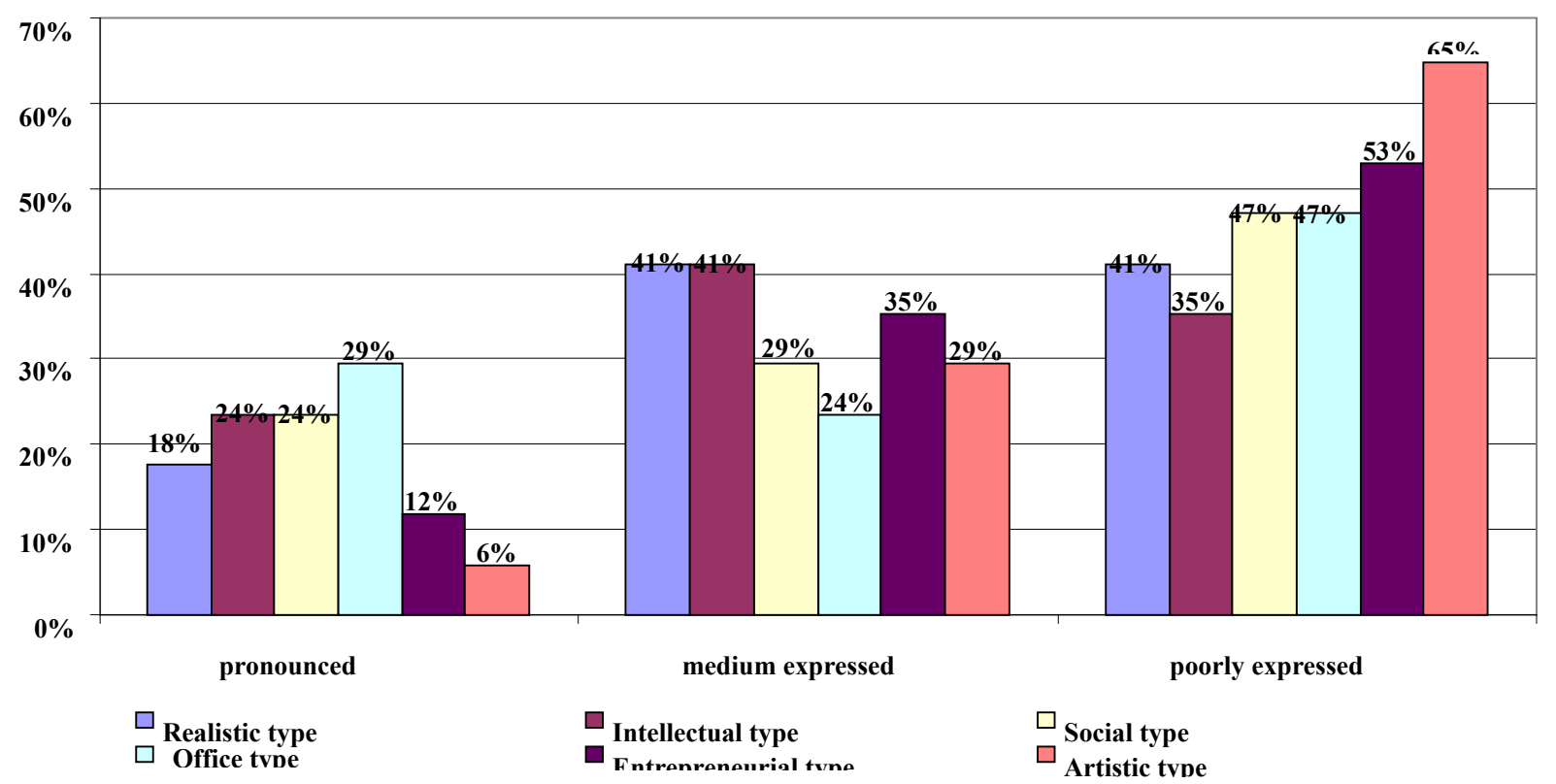

Figure 1. Definition of professional type of the personality by J. Golland

After carrying out the testing with the former military personnel the practical course "How to make the curriculum vitae" was delivered.

The curriculum virtae or the summary is a special instrument which influences the employer long before the personal meeting. The purpose of this summary is to create a favorable impression. Information provided in the summary should be selected according to the main objectives. The summary made correctly is one of the main 
reasons for the job interview.

Further the course "Examples of Answers to the Typical Questions of Interviews" was carried out with the former military personnel. Each participant acted as a competitor for a vacant post and was given a number of questions he had to answer taking into consideration the offered examples.

The courses on socio-professional adaptation should be organised in the form of creative games within the modelled typical situations which a former military man come across or can come across in the course of job search, with the subsequent reflexive analysis and discussion of the received results, finishing each course by a self-control session.

\section{Discussions}

The problem of adaptation of the military personnel transferred to the reserve as the form of the social workers' activity is displayed in the works of many scientists: professional adaptation of the military personnel transferred to the reserve" (Gatvinsky \& Slabnina, 2002; Zheleznyakov, 2010; Kadnichanskaya, 2002; Razov, 2010; Obertenyuk, 2007; Shamiyeva, 2009), social adaptation of the military personnel transferred to the reserve (Rodyukov, 1999; Cheplyaev, 1999; Shigov, 2005), socio-psychological adaptation (Dmitriyev, 1999; Osukhova, Lotova, \& Kalinichev, 2001), professional guidance, reorientation (Petrov, 1998; Popova, Fedotova, \& Cheplyaev, 1994; Rodyukov, 2000, Malinin, Chinyaev, \& Maltsev, 1995), social protection of the military personnel (Gerasimov, 1991; Degot \& Semenets, 1997; Serebryakova, 2008; Tishchenko, 2004), technologies of social work with the military personnel (Pavlenok, 2011, Kholostova, 2011) etc. However socio-professional adaptation of the military personnel transferred to the reserve after carrying out the second stage of the reforms of the system of Armed Forces of the Russian Federation is poorly featured in the Ulyanovsk region.

\section{Conclusion}

Socio-professional adaptation of the military personnel transferred to the reserve to a new professional activity (or a new workplace) will be more effective if in the course of practical work certain psychological resources and qualities promoting formation of independence of the personality become realized. Among them there are:

- activity,

- initiative,

- flexibility and mobility,

-ability to regulate one's own behavior and emotional reactions,

-ability to keep one's own opinion contrary to external pressure,

tendency to take the responsibility for the most important events of one's life, but not to blame for them other people or destiny.

When a person has the conscious intention to disclose his/her own creative potential for the purpose of adaptation of the chosen profession to oneself (an active form of adaptation) on the basis of its strong-willed organization and active and creative tendency, the changing factors of the environment would stop being perceived as stressful.

The developed system of events and resources will allow reducing the period of socio-professional adaptation for the military personnel transferred to the reserve. It raises their self-assessment and resistance to stresses.

The results of the held events were used for creating the general algorithm of work on socio-professional adaptation of the former military personnel.

1) Diagnostic block: each participant should study the research of the personal and motivational sphere, the sphere of values orientations, the possible level of personal claims and adaptation reserves.

2) Information block: monitoring of Labor market, the prospect of its development, career guidance within the table of correspondences of military and civil professions.

3) Block of social and role interaction: creative professional orientation role-playing and organizational and activity games promoting the development of coping behavior and reaction, personal independence, and also an effective role interaction within the social group.

4) Psycho-correction block: training the skills of dissociation, reflection of significant identifications, actual needs, etc.

5) Block of exercises on working off skills of self-regulation

6) Final diagnostics. 
Following the given algorithm military personnel transferred to the reserve could easier pass socio-professional adaptation.

\section{Recommendations}

The results of the research given in the article can be used by the experts of military commissariats, job centers, social workers, whose professional activity is connected with the military personnel transferred to the reserve.

\section{References}

Cheplyaev, V. L. (1999). Social adaptation of military personnel. Human Resources, 1-2.

Degot, B. A., \& Semenets, N. Ya. (1997). Social protection of the citizens discharged from military service. Saratov: PMUTs.

Dmitriyev, I. V. (1999). Social and psychological adaptation of the officers transferred to the reserve to the conditions of the civil environment ( $\mathrm{PhD}$ thesis). Moscow.

Gatvinsky, A. N., \& Slabnina, E. V. (2002). Professional adaptation of the military personnel transferred to the reserve. Saratov: PMUTs.

Gerasimov, A. V., \& Loza, G. G. (1991). Social security of the Soviet military personnel. Moscow: Voyenizdat.

Kadnichanskaya, M. I. (2002). Labor adaptation of reserve officers of Armed Forces of the Russian Federation in the reformed society ( $\mathrm{PhD}$ thesis). Ulyanovsk.

Kholostova, E. I. (2011). Technology of Social Work. Moscow: Yurite.

Malinin, A. V., Chinyaev, D. V., \& Maltsev, V. E. (1995). Career guidance and social support of the military personnel transferred to the reserve. Saratov: Saratov regional jobcenter of the population.

Obertenyuk, V. G. (2007). Adaptation strategies of behavior of the leaving and dismissed military personnel under modern Russian conditions. News of higher educational institutions. The North Caucasian region: Social sciences.

Osukhova, N. G., Lotov, I. P., \& Kalinichev, V. L. (2001). Social and psychological adaptation of the military personnel transferred to the reserve or resignation, theory and practice. Moscow.

Pavlenok, P. D. (2011). Technologies of social work with various categories of population. Moscow: Infra-M.

Petrov, V. P. (1998). Vocational guidance and employment of the citizens discharged from military service. Berlin: TACIS.

Popova Z. N., Fedotova N. N., \& Cheplyaev V. L. (1994). Psychological and pedagogical features of professional retraining of adults. Saratov.

Razov, P. V. (2010) Social protection of the citizens discharged from military service as social institute. The Bulletin of Military University, 3(23).

Reform of Armed forces of Russia. (2008-2020). In Wikipedia, free encyclopedia. Retrieved Marth 15, 2015, from https://ru.wikipedia.org/wiki/_Реформа_Вооружённых_сил_России_

Rodyukov, E. B. (1999). Social adaptation of military personnel of the reserve. In Collection of materials: Recommendations, researches, documents. Moscow.

Rodyukov, E. B. (2000). How to find the work. In The methodical manual (advice to the military personnel, citizens discharged from military service and members of their families concerning employment and retraining). Moscow.

Serebryakova, N. A (2008). The system of social protection of military personnel. Bulletin of the Saratov State Technical University, 1(1).

Shamiev V. A. (2009). Adaptation and symptoms of aggressiveness among recruits. Bulletin of Tomsk State Pedagogical University, 2.

Shigov, M. (2005). Experience of social adaptation of retired military personnel in some NATO countries (Vol 3). Foreign Military Review.

Socio-Professional adaptation. (2015). Retrieved March 15, 2015, from http://vslovare.ru/slovo/psihologicheskiij-slovar/sotzialno-professionalnaja-adaptatzija/237091

Surkov, R. V., Shabanova, O. V., \& Chertushkina, T. A. (2011). Social work with military men. Ulyanovsk.

Tishchenko, A. G. (2004). Realization of the right to choose one's residence at dismissal from military service by 
the military men. Right in the Armed Forces, 4.

Zheleznyakov, A. M. (2010). The analysis of practical experiment on socio-professional adaptation of the officers transferred to the reserve. Social policy and social partnership, 6 .

\section{Copyrights}

Copyright for this article is retained by the author(s), with first publication rights granted to the journal.

This is an open-access article distributed under the terms and conditions of the Creative Commons Attribution license (http://creativecommons.org/licenses/by/3.0/). 